\title{
Dose Response of Arginine Vasopressin to the CCK-B Agonist Pentagastrin
}

\author{
James L. Abelson, M.D., Ph.D., Jean-Michel Le Mellédo, M.D., and Daniel G. Bichet, M.D., FRCPC
}

Cholecystokinin (CCK) is a peptide neurotransmitter that modulates hypothalamic-pituitary-adrenal (HPA) axis activity and may be involved in fear or anxiety states. Arginine vasopressin (AVP) also modulates HPA axis activity and may play a role in fear conditioning. Few human studies have examined interactions between CCK and AVP systems. To explore relationships between CCK-B receptor activation, the HPA axis response, and AVP release, a dose-response study using the CCK-B receptor agonist pentagastrin was conducted. Adrenocorticotropin $(A C T H)$ and cortisol results have been previously reported and AVP data is presented here. Thirty-five healthy subjects were randomly assigned to receive placebo, or 0.2, $0.4,0.6$, or $0.8 \mu \mathrm{g} / \mathrm{kg}$ doses of pentagastrin. AVP release appeared to increase with increasing doses of the CCK-B agonist. However, this may have been due to a greater percentage of subjects releasing AVP in the higher dose groups, rather than a direct effect of dose on magnitude of response. AVP and ACTH responses were correlated, but $A V P$ response alone could not account for the magnitude of the ACTH response. AVP release was significantly correlated with anxiety symptom responses. These findings suggest a possible role for the CCK-B receptor in AVP release, which may be at least partially separate from its role in modulation of the HPA axis. Further work is needed to determine whether these are physiologically meaningful interactions and to determine their functional implications. [Neuropsychopharmacology 24:161-169, 2001] (C) 2000 American College of Neuropsychopharmacology. Published by Elsevier Science Inc.
KEY WORDS: Cholecystokinin; Vasopressin; Pentagastrin; Anxiety; Panic disorder

Cholecystokinin (CCK) is a peptide neurotransmitter that is widely distributed in brain areas involved with cognitive or emotional aspects of behavior, such as prefrontal cortex, cingulate, hippocampus, amygdala, and the locus coeruleus (Lindefors et al. 1993; Saito et al. 1980). Some evidence suggests it may modulate stress responsiveness,

From the University of Michigan Department of Psychiatry, Anxiety Disorders Program, Ann Arbor, MI (JLA); Department of Psychiatry, University of Alberta, Edmonton, Alberta, Canada (JMLM); and University of Montreal, Hôpital Sacré-Coeur, Montreal, Quebec, Canada (DGB).

Address correspondence to: James L. Abelson, M.D., Ph.D., Rm C435, Med Inn Bldg/0840, 1500 E. Medical Center Drive, Ann Arbor, MI 48109-0840.

Received 24 January 2000; revised 4 May 2000; accepted 19 July 2000 . functioning as a neuromodulator of the hypothalamicpituitary-adrenal (HPA) axis (Abelson and Liberzon 1999). CCK-B agonists, such as pentagastrin, activate the HPA axis in humans, stimulating release of adrenocorticotropin $(\mathrm{ACTH})$ and cortisol (Abelson and Liberzon 1999; Abelson et al. 1994; de Montigny 1989; Degli Uberti et al. 1983; Späth-Schwalbe et al. 1988).

Levels of CCK and corticotropin-releasing hormone (CRH) were found to be correlated in human cerebrospinal fluid, suggesting that central regulation of these two neuropeptides may be linked in humans; and this linkage may be tighter under conditions of stress (Geracioti et al. 1999). Animal work also demonstrates substantial interaction between CCK and the HPA axis. The axis is directly sensitive to CCK activation (Kamilaris et al. 1992; Matsumura et al. 1983; Mezey et al. 1986; Reisine and Jensen 1986); and CCK peptide is colocalized with other HPA axis secretagogues (Kiss et al. 1984; Larsson and Rehfeld 1981; Mezey et al. 1986; Mill- 
ington et al. 1992; Rehfeld 1978; Rehfeld and Larsson 1981; Rehfeld et al. 1987; Vanderhaeghen et al. 1985). Central CCK systems are stress and glucocorticoid sensitive (Mezey et al. 1986; Siegel et al. 1987); and peripheral CCK can regulate activity in central components of the HPA axis (Chen et al. 1993).

Though CCK-HPA axis interactions are well established, the mechanisms by which they interact remain uncertain. Central regulation of the HPA axis is exerted primarily through corticotropin-releasing hormone $(\mathrm{CRH})$, arginine vasopressin (AVP), and negative glucocorticoid inhibition (Aguilera 1994). Animal work suggests that both CRH (Biró et al. 1993; Kamilaris et al. 1992) and AVP (Bondy et al. 1989; DeBold et al. 1984; Mezey et al. 1986; Verbalis et al. 1987) could mediate CCK effects on the HPA axis. However, due to substantial cross species variation in CCK function (Hinks et al. 1995; Woodruff et al. 1991), human studies will be needed to clarify these mechanisms in humans. CCK-induced release of ACTH differs from that seen with human CRH in its rapidity, brevity, and relative resistance to cortisol feedback inhibition (Abelson and Liberzon 1999; DeCherney et al. 1985; Hermus et al. 1984; Schürmeyer et al. 1984), raising questions about the role of CRH as mediator of the human HPA response to CCK agonism. A very rapid and robust release of AVP is seen in humans after CCK agonist injection (Le Mellédo et al. 1997; Miaskiewicz et al. 1989), supporting its potential role as mediator of CCK activation of the HPA axis. No human studies to date have simultaneously examined both ACTH and AVP responses to CCK receptor agonists.

Functional interactions between CCK, AVP, and the HPA axis could be important to our understanding of a number of clinical conditions. The CCK-B receptor is thought to play a role in anxiety states (Bradwejn and Koszycki 1994; Harro et al. 1993) and CCK-B agonists reliably elicit panic attacks in the laboratory (Abelson and Nesse 1994; Bradwejn et al. 1991; de Montigny 1989). Panic patients show subtle abnormalities in HPA axis activity (Abelson and Curtis 1996), similar to those seen in patients with depression (Linkowski et al. 1985). Recent work suggests that HPA axis dysregulation in depression may be associated with a shift towards increased vasopressinergic control of the axis (Dinan et al. 1999; Holsboer and Barden 1996). Abnormalities in AVP levels or receptor activity have been detected in depression (Purba et al. 1996; van Londen et al. 1997) and obsessive-compulsive disorder (Altemus et al. 1992), but have not yet been studied in other anxiety disorders. Evidence that AVP may play a role in conditioned fear (Stoehr et al. 1993), avoidance learning (Insel et al. 1999), and novelty sensitivity (Ehrenreich et al. 1996) suggests a possible relevance to phobic behavior and panic. An AVP antagonist has shown some anxiolytic activity in an animal model (Liebsch et al. 1996).

Given the pharmacological and neuroanatomical links, and potential relevance to mood and anxiety disorders, further exploration of interactions between CCK, AVP, and the HPA axis are warranted. We have recently demonstrated in human subjects that the CCK$\mathrm{B}$ agonist pentagastrin releases ACTH and cortisol in a dose-dependent fashion (Abelson and Liberzon 1999). We have also shown that another CCK-B agonist (CCK4) can release AVP in humans (Le Mellédo et al. in press). To determine whether pentagastrin stimulates AVP release in a dose-dependent fashion and whether AVP participates in the ACTH response to pentagastrin, we have now also examined plasma AVP responses following varying doses of intravenous pentagastrin.

\section{METHODS}

\section{Subjects}

As previously described (Abelson and Liberzon 1999), subjects were 19 female and 16 male healthy adults, with a mean age of $26.3 \pm 7.7$ years (range, 18-45 years). They were recruited through newspaper advertising, screened using the Structured Clinical Interview for DSM-IV (SCID) to insure the absence of psychiatric disorders, and paid $\$ 100$ for their participation. An abbreviated Family Informant Schedule and Criteria interview (Mannuzza et al. 1985) was used to exclude those with affective or anxiety disorders in first degree relatives. Subjects had no recent (three months) serious medical illness, no history of alcohol or drug dependence, and no recent (six months) drug or alcohol abuse. They did not smoke more than 20 cigarettes per day or drink more than four cans of beer (or the equivalent) per week in the past 6 months. They were within $-10 \%$ and $+25 \%$ of ideal body weight, had a negative urine drug screen, and had normal screening laboratory tests (blood counts, electrolytes, glucose, liver and renal functions). Female subjects were pre-menopausal, were not taking birth control pills, and were studied within the first 10 days after the onset of menstruation (to preclude the possibility of pregnancy and control for effects of menstrual cycle on the HPA axis). All subjects provided written informed consent.

\section{Procedures}

Subjects were assigned (by constrained random assignment to give approximately equal age and gender distributions in each group) to a placebo group or one of four dose groups $(0.2,0.4,0.6$, and $0.8 \mu \mathrm{g} / \mathrm{kg})$. The selection of doses was based on the study's primary focus on ACTH and cortisol (Abelson and Liberzon 1999). Subjects and nursing staff were blind to group assignment. The experiment was conducted in a General Clinical Research Center (GCRC), where subjects were ad- 
mitted at 1:00 p.m. An intravenous catheter was inserted into a forearm or antecubital vein and kept open with a normal saline drip. Subjects rested comfortably in bed, following IV insertion, for a 2-hour accommodation period. Baseline blood samples were obtained at 3:00 p.m. and 3:28 p.m. Pentagastrin (Wyeth-Ayerst Laboratories, Philadelphia, PA), in a saline vehicle of less than $5 \mathrm{ml}$, was injected via the IV at 3:30 p.m. over 10 to 15 seconds. Additional blood samples were obtained at 3, 5, 10, 20,30, 45, and 60 minutes after the injection. Samples were drawn into heparinized vacutainer tubes and were immediately placed on ice. They were spun (10 minutes at $3000 \mathrm{rpm}$ ) in a refrigerated centrifuge within 30 minutes and plasma was immediately separated and frozen at $-70^{\circ}$.

\section{Measures and Assays}

Physical and emotional symptoms were recorded, at the time of each blood sample, using a previously described (Abelson and Nesse 1994) version of the Acute Panic Inventory (Dillon et al. 1987) and visual analog scales (VAS). The modified API provides self-report ratings on a 4 point scale (none, mild, moderate, severe) of subjective and somatic symptoms of panic attacks as listed in DSM-IV. We used total symptom intensity (sum of individual symptom ratings) as our primary dependent variable from the API. For the VAS scales subjects rate themselves on 10 feeling states by marking a line on a $100-\mathrm{mm}$ visual analog scale ranging from "not at all" to "most ever". A composite measure of anxious distress was calculated by summing the VAS measurements for "anxious", "nervous", and "fearful", and subtracting the measure for "calm".

Heart rate (HR), systolic blood pressure (SBP), and diastolic blood pressure (DBP) were measured using an AirShields automated monitor, as previously described (Abelson and Liberzon 1999).

Vasopressin was measured, in a subset of the samples drawn (baseline and 3, 5, 10, 20, and 45 minutes after pentagastrin), using a radio-immunoassay developed in Dr. Bichet's laboratory (Bichet et al. 1986). Plasma samples were extracted with the petrol-ether method, evaporated to dryness and reconstituted in 750 $\mu \mathrm{L}$ of buffer. Duplicate tests were conducted on $200 \mu \mathrm{L}$ of reconstituted sample. The assay sensitivity was 0.1 $\mathrm{pg} /$ tube $(0.5 \mathrm{pg} / \mathrm{mL})$ with a $50 \%$ displacement of the tracer (iodinated-AVP from Amersham) obtained for $1.2 \mathrm{pg} /$ tube. The antiserum (AS-2849) was used at a final dilution of $1 / 2.5 \times 10^{6}$. The standard curve included six Bo and 10 concentrations in triplicates. Intraand inter-assay coefficients of variation for AVP plasma concentrations between 2 and $5 \mathrm{pg} / \mathrm{mL}$ were less than $10 \%$. Non-specific binding (with the charcoal separation method) was less than 3\%. Cold vasopressin was added to plasma from patients with central diabetes insipidus to calculate recoveries (done with every assay).

\section{Analyses}

AVP data were log-transformed prior to analysis. The primary test of dose group effects used an integrated response measure, calculated for each subject by determining the area under the post-injection curve (using trapezoidal approximation) and subtracting the area under the pre-injection curve (multiplied by a constant to approximate the same time duration as the postinjection curve). One-way analysis of variance (ANOVA) was used to determine whether the dose groups differed on this response measure and Fisher's PLSD posthoc tests were used to specifically locate the groups that differed when the group main effect was significant. A follow-up repeated-measures ANOVA, with dose group as a between subject variable and time (two preinjection and five post-injection measures) as a within subjects variable, was used to allow detection of dose group differences in pattern of response to pentagastrin, reflected in a group-by-time interaction in this analysis. Relationships among AVP release, ACTH/ cortisol release, and dose were examined using Pearson product-moment correlations and multiple or step-wise regression analyses. Peak response or post-pentagastrin peak levels of hormone were used in these analyses. Pearson product-moment correlations were also used for exploratory assessment of relationships between hormonal and symptom/emotional responses. Symptom responses were calculated as the difference between the 3-minute post-injection rating (maximal symptom point for all subjects) and the mean baseline.

\section{RESULTS}

As previously reported (Abelson and Liberzon 1999), the five dose groups did not differ significantly in mean age, sex distribution, height, weight, and scores on psychological screening inventories ( $p>.22$ for all tests). They also did not differ in basal AVP levels $(\mathrm{F}=0.96 \mathrm{df}$ $=4,30, p=.44)$. There were no differences between males and females in AVP levels, examining basal, peak, and response measures ( $p>.42$ for all tests).

An impact of pentagastrin dose on AVP release is readily apparent in the net integrated response data (raw data, prior to log transformation, are presented in Figure 1). One-way ANOVA showed a significant main effect of group $(\mathrm{F}=3.39, \mathrm{df}=4,30, p=.02)$. Fisher's PLSD post-hoc tests showed that the highest dose group $(0.8 \mu \mathrm{g} / \mathrm{kg})$ differed significantly $(p=.01)$ from the placebo group and the two highest dose groups ( 0.6 and 0.8 $\mu \mathrm{g} / \mathrm{kg}$ ) both differed significantly from the lowest dose group $(0.2 \mu \mathrm{g} / \mathrm{kg}, p=.03$ and .004 , respectively). Exam- 
ination of individual subject data for each dose group (included in Figure 1) suggests that the dose effect is due to an "on-off" or threshold effect in which increased numbers of subjects release AVP at higher doses, without a clear-cut dose effect on magnitude of the response.

The timing of the AVP response can be seen in the group by time data presented in Figure 2. The dose effect was confirmed by repeated measures ANOVA using these data, with a highly significant group-by-time interaction $(\mathrm{F}=3.99, \mathrm{df}=24,180, p<.0001)$ and a nearly significant main effect of dose group $(\mathrm{F}=2.55$, $\mathrm{df}=4,30, p=.059)$. A significant main effect of time ( $\mathrm{F}=$ $14.17, \mathrm{df}=6,180, p<.0001)$ reflects the robust release of AVP following pentagastrin in some subjects. In all subjects who respond (individual data not shown), the AVP peak is seen in the +3 minute sample and returns to baseline by 20 minutes after injection.

Cardiovascular and symptom responses have been previously reported (Abelson and Liberzon 1999). Briefly summarized, pentagastrin produced significant rises in HR and $\mathrm{BP}$ that were not clearly dose-depen- dent. It also produced significant increases in panic attack symptoms, symptom intensity, and anxious distress. Symptom responses were higher in the 3 highest dose groups, which did not differ significantly from each other.

AVP response was significantly related to both ACTH and cortisol responses $(r=0.55, p=.0008$; and $r=$ $0.54, p=.0009$, respectively, $n=35)$, but accounted for only $30 \%$ and $29 \%$ of the variance $\left(\mathrm{r}^{2}\right)$ in these responses. The AVP response was also significantly related to dose of pentagastrin $(\mathrm{r}=0.50, p=.002, n=35)$, panic symptom intensity response $(\mathrm{r}=0.57, p=.0003$, $n=35)$, and increase in anxious distress $(\mathrm{r}=0.38, p=$ $.03, n=35$ ). Since symptom responses were also related to dose, these variables were also analyzed in a multiple regression. Dose, anxious distress, and symptom intensity together accounted for $40 \%$ of the variance in AVP response (multiple $\mathrm{r}=0.63, p=.001, n=35$ ), but only panic symptom response was a significant, independent predictor $(p<.02$ for panic symptom intensity, $p=.17$ for anxious distress, and $p=.27$ for dose).

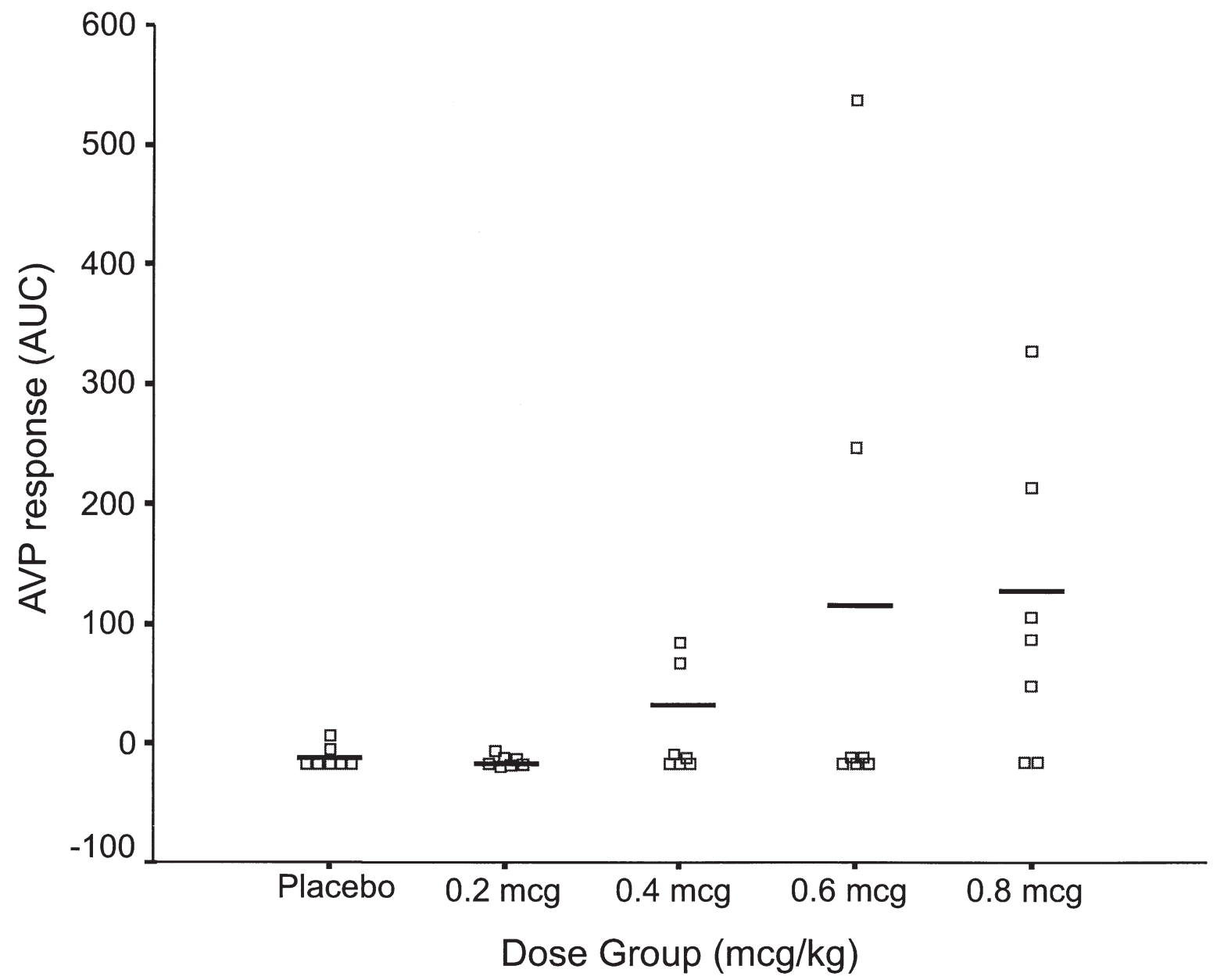

Figure 1. Net vasopressin (AVP) responses (calculated as area under the curve, AUC) to placebo or four different doses of pentagastrin in separate groups of healthy control subjects ( $n=7$ per group). Group means are indicated by solid lines. Individual subject data are presented in squares. 


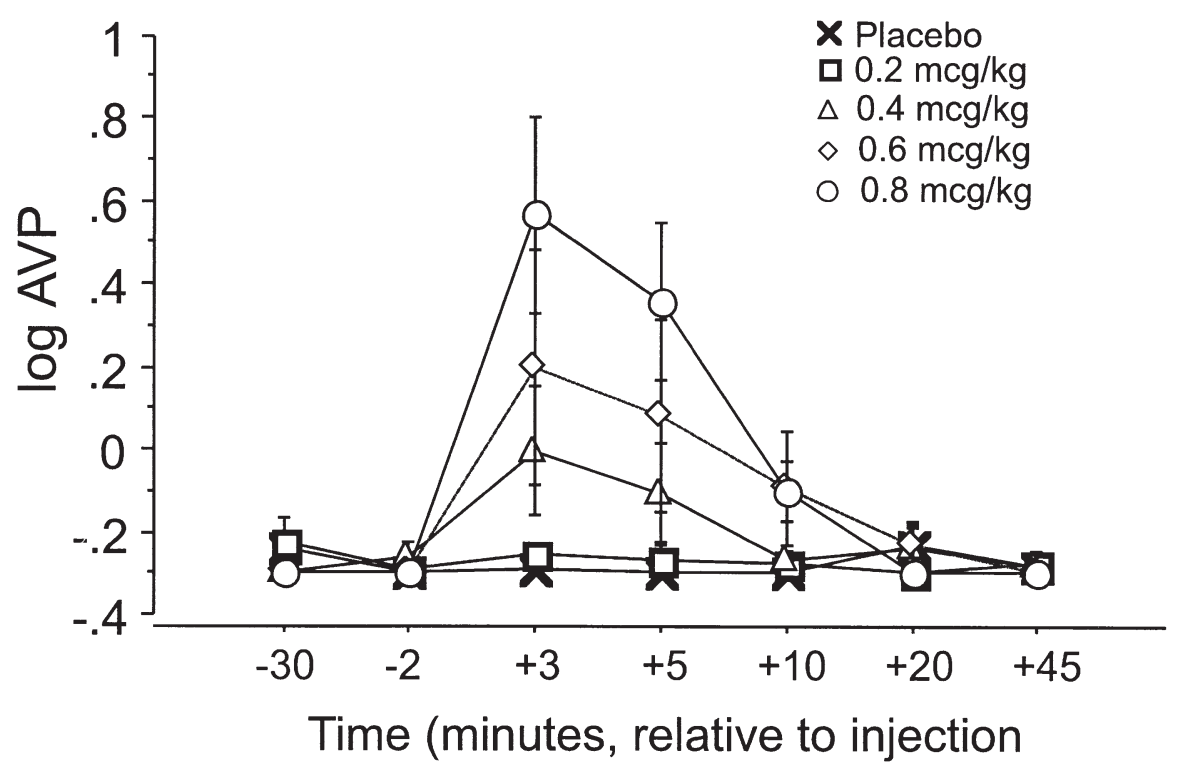

Figure 2. Vasopressin (AVP) responses to placebo or four different doses of pentagastrin in separate groups of healthy control subjects ( $n=7$ per group). Log transformed AVP values ( \pm standard error) are presented. The time scale ( $x$ axis) is distorted to stretch distance between sampling points close in time and allow clearer visualization of the response curves.
The significant relationship between symptoms and AVP response, which appears independent of dose effects, contrasts with previously reported ACTH and cortisol data. Panic symptom intensity did predict ACTH and cortisol responses to pentagastrin $(r=0.49$, $p=.004$; and $\mathrm{r}=0.50, p=.002$, respectively, $n=35$ ), but this relationship disappeared when controlled for dose (Abelson and Liberzon 1999). When symptom response and ACTH response were entered into a multiple regression with AVP response as the dependent variable, the two predictors accounted for $41 \%$ of the variance in AVP response (multiple $\mathrm{r}=0.64, p=.0003$, $n=34)$ and both had independent predictive power $(p=$ .02 and .03 , respectively).

To further explore the role of AVP as a potential mediator of the ACTH response to the CCK-B agonist, a step-wise regression was performed with ACTH response as the dependent variable. Since ACTH response was strongly related to dose, this was entered first and the AVP and symptom responses were added to assess their additional predictive power. Both dose and AVP entered the model, making significant, independent contributions to the ACTH response $(p<$ .0001). Symptom response did not contribute any additional predictive power. Finally, we calculated the degree of overlap between those subjects mounting an AVP response and those mounting an ACTH response. We defined AVP "responders" as subjects with a postpentagastrin AVP peak of greater than $5 \mathrm{pg} / \mathrm{ml}$ and ACTH "responders" as subjects with at least a $25 \mathrm{pg} /$ $\mathrm{ml}$ rise in ACTH from baseline to post-pentagastrin peak. Six of the seven subjects with an AVP response also had an ACTH response (86\%). However, eight of 14 subjects with ACTH responses did not have an AVP response $(57 \%)$ and six of these did not have measurable plasma levels of AVP at any point.
There were no significant relationships between AVP response to pentagastrin and HR, SBP, or DBP responses ( $p=.42, .10$, and .64 , respectively). The majority of subjects who had heart rate responses to pentagastrin (at least 5 beat per minute increase from baseline) did not have measurable plasma levels of AVP at any point (13 of 21 subjects). Most of the subjects who did not have AVP responses did have either a HR or ACTH response (20 of 28).

There was a low, but significant relationship between peak AVP levels following pentagastrin and gastrointestinal (nausea/upset stomach) symptom intensity ratings $(\mathrm{r}=0.36, p=.04, n=35)$. Those subjects with AVP peaks greater than $5 \mathrm{pg} / \mathrm{ml}(n=7)$ tended to have higher ratings of gastrointestinal symptoms $(\mathrm{t}=$ $1.88, p=.07, \mathrm{df}=33$ ) than those with lower AVP peaks. This relationship was not unique to gastrointestinal symptoms, as respiratory (short of breath/smothering, $\mathrm{r}=0.53, p=.001$ ), autonomic (trembling/sweating, $\mathrm{r}=$ $0.37, p=.03)$, temperature $(\mathrm{r}=0.37, p=.03)$, cardiac (heart racing/chest discomfort, $\mathrm{r}=0.41, p=.01$ ), and cognitive (fear of dying/going crazy/losing control, $r=$ $0.44, p=.009$ ) symptoms were also related to AVP levels $(n=35$ for all). The AVP responders had significantly higher ratings of respiratory distress $(\mathrm{t}=3.3, p=$ $.002, \mathrm{df}=33)$ and cognitive fear symptoms $(\mathrm{t}=2.4, p=$ $.02, \mathrm{df}=33)$ than did AVP non-responders.

\section{DISCUSSION}

These data document that a specific CCK-B receptor agonist elicits robust AVP secretion in some subjects. This release appears dose-related, though the data do not clearly indicate whether the magnitude of the AVP response is indeed a function of pentagastrin dose. There 
may be individual variation in threshold for AVP release, with higher doses surpassing a release threshold in more subjects, but not necessarily eliciting larger responses. However, further work with larger groups and higher doses is needed to fully characterize the dose-response relationship. We do not know whether the highest dose used in this study was able to elicit maximal AVP responses from all subjects capable of responding. The effect of pentagastrin dose on AVP release may appear different if a broader dose range is utilized.

Though further work is needed to more fully characterize the dose-response curve, these data do suggest a pharmacological relationship between CCK receptor activation and AVP release, which is consistent with prior work in this area. In vitro studies have shown that rat neural lobe neurons contain high affinity CCK binding sites and that activation of these sites releases AVP (Bondy et al. 1989). In intact rats, intracerebroventricular administration of CCK-8 increases plasma levels of AVP (Morawska-Barszczewska et al. 1996). In primates, peripheral administration of CCK-8 increases plasma levels of AVP (Verbalis et al. 1987). In humans, both CCK-8 and CCK-4 have been shown to increase plasma AVP levels (Calogero et al. 1993; Le Mellédo et al. in press; Miaskiewicz et al. 1989).

The mechanisms of CCK - AVP interactions remain uncertain. One direct mechanism by which CCK-B agonism could release AVP would be via CCK-B receptors in the posterior pituitary. Both CCK immunoreactivity and CCK binding sites are found in the posterior pituitary (Beinfeld 1983; Woodruff et al. 1991), which is accessible to peripherally administered pentagastrin. As noted above, in vitro work has shown that high affinity CCK binding sites in the posterior pituitary, most likely of the CCK-B subtype, potently trigger AVP release when activated (Bondy et al. 1989). Hypothalamic CCK-B-receptor mediated effects, via receptors in supraoptic or paraventricular nuclei (Beinfeld 1983), are also possible, but the extent to which pentagastrin can penetrate the blood-brain barrier is uncertain. A different central site of action has been proposed for intravenous CCK-4 (Bradwejn et al. 1994), which differs from pentagastrin by only one amino acid - in brainstem regions that contain CCK pathways and are not fully protected by the blood-brain barrier (e.g., nucleus tractus solitarius). Centrally mediated release would likely require hypothalamic activation and either neuronal stimulation of AVP release from the posterior pituitary or AVP release from the median eminence into the portal circulation. If the latter pathway were active we would expect a tighter relationship between AVP and ACTH levels, since portal AVP plays an active role in ACTH release from the anterior pituitary. This relationship, however, was fairly weak in our data. Further studies will be needed to determine whether pentagas- trin can in fact reach central sites and effect AVP release via central mechanisms. At present, a pituitary level effect appears more likely.

Nausea is a potential mediating mechanism, since CCK agonists can induce nausea and AVP release may be associated with activation of central pathways that mediate nausea (Verbalis et al. 1987). We did find a small, but significant correlation between post-pentagastrin AVP levels and ratings of gastrointestinal distress. However, we also found a more general relationship between subjective symptom reports and AVP levels. Respiratory distress and cognitive anxiety ratings in fact provided stronger predictors of AVP levels than nausea. This suggests the hypothesis that general distress generated by a variety of physical symptoms, and not specific to nausea, may be linked to AVP release.

Our data do not support AVP as the primary mediator of the ACTH response to pentagastrin. We did find a significant relationship between post-pentagastrin AVP levels and ACTH response, but the relationship was not particularly strong and accounted for a small percentage of the variance in ACTH response. There were a substantial number of subjects who had clear ACTH responses without measurable plasma levels of AVP. Caution in needed, however, in extrapolating from peripherally measured hormone levels to activity at critical, more central site(s) of action. We can only definitively conclude that sufficient AVP release to produce measurable levels in the peripheral circulation does not appear necessary to elicit a strong ACTH response to a CCK-B agonist.

As noted above, it is not likely that the AVP measured in this study came primarily from the portal circulation. The median eminence/portal pool of AVP is directly linked to ACTH release (Hensen et al. 1988), and if this were the source of AVP in our subjects we would expect a much tighter link to ACTH levels. Posterior pituitary AVP is released into the peripheral circulation and comprises a separate pool, which probably does not directly influence ACTH release. Much higher levels of peripherally measured AVP are usually needed before an AVP-mediated ACTH response is elicited (Hensen et al. 1988). If the posterior pituitary was the source of the AVP response to pentagastrin in our subjects, then the weak relationship with ACTH release that we did detect could be explained by the presence of CCK-B receptors, with similar sensitivities, in both the anterior and posterior pituitary. However, it is also conceivable that even low levels of AVP reaching the anterior pituitary via the peripheral circulation could have a modulatory effect on CRH-mediated ACTH release, for example, by shortening the latency to response (Born et al. 1995; Kellner et al. 1995; Le Mellédo et al. in press). The rapidity of the ACTH response to pentagastrin does differentiate it from the 
ACTH response to exogenous CRH (Abelson and Liberzon 1999). The time frame of the AVP response to pentagastrin, peaking at 3 minutes in this and a prior study (Le Mellédo et al. in press), is consistent with an influence on the timing of the ACTH response, which peaks at 6 minutes (Abelson and Liberzon 1999). Further work is needed to clarify more precisely the exact relationships between CCK, AVP, and ACTH release.

Though our data support a dose effect on release of AVP in response to pentagastrin, they also suggest that individuals may vary in their dose threshold for releasing AVP after CCK-B receptor activation. Individual variability in threshold for AVP release did not appear to be a function of general CCK-B receptor sensitivity in our subjects. If this were the case, those subjects who did not respond to pentagastrin with AVP release should also have had reduced responses in other systems. They did not, as the majority of subjects who were not AVP responders had preserved cardiac or $\mathrm{ACTH}$ responses to the agonist. Interestingly, AVP "responders" did show higher levels of respiratory distress and cognitive anxiety, whereas these variables were not as robustly linked to ACTH or cardiac responses. Further work, using within subject designs and including higher doses of pentagastrin, will be needed to test the threshold hypothesis and determine whether threshold for AVP response to CCK agonists is a stable, trait characteristic of human subjects. If it is, further exploration of phenotypic correlates and biological determinants could prove fruitful. Vulnerability to anxious distress may be one phenotypic correlate that merits further study.

Current data show a consistent relationship between peak AVP levels following pentagastrin and measures of subjective symptom intensity across multiple physiological systems, including cognitive symptoms of panic anxiety. The post-hoc nature of this finding suggests caution and a need for replication, but given prior difficulty establishing reliable links between peripheral endocrine measures and subjective behavioral or emotional states, follow-up is important. There is strong neuroanatomical, physiological, and behavioral evidence that AVP may mediate behavioral and emotional aspects of anxiety and stress (Davis 1998; de Wied et al. 1993; LeDoux 1998; Liebsch et al. 1996). Central AVP release may in fact provide one mechanism through which an emotional stressor can modulate HPA axis activity (Wotjak et al. 1996). However, in this study we were likely detecting peripheral, not central, AVP release. The link between peripherally measured AVP levels and anxiety symptoms could reflect simultaneous co-activation of CCK-B receptors at peripheral sites (e.g., posterior pituitary) and unprotected central sites (e.g., nucleus tractus solitarius). It is also conceivable that non-specific "stress" effects of the experimental paradigm and experience could produce hypotha- lamic neuronal activity that contributes both to symptom production and priming of neurohypophyseal AVP neurons in a way that sensitizes them to activation. Alternatively, it is possible that peripherally released AVP is actively transported into the brain where it has behavioral effects.

Further work is needed to verify whether AVP release is in fact linked to emotional and behavioral responses and to determine the nature and functional meaning of any such linkage. Follow-up work needs to move beyond correlation analyses, to test specific hypotheses using more direct manipulations of cognitive and emotional responding to specific stressors and pharmacological challenges. A simple cognitive manipulation, for example, has been shown to alter HPA axis activity in a laboratory model of panic, in both panic patients and control subjects (Abelson et al. 1996). The current findings suggest the hypothesis that AVP may be even more sensitive to such manipulations than $\mathrm{ACTH}$ and cortisol.

\section{ACKNOWLEDGMENTS}

This research was supported by a grant from the National Institute of Mental Health (R29MH52724) and a Clinical Research Center grant from the National Institute of Health (MO1RR00042). Elizabeth A. Young, M.D. assisted in the development of this project and review of the manuscript. Hedieh Briggs, M.S.W. was essential to the execution of the study. The University of Michigan GCRC nurses, and particularly Kathleen Jarvenpaa, R.N., B.S.N., played critical roles in data collection. Israel Liberzon, M.D. provided invaluable aid in preparation of this manuscript.

\section{REFERENCES}

Abelson JL, Curtis GC (1996): Hypothalamic-pituitary-adrenal axis activity in panic disorder: 24-hour secretion of corticotropin and cortisol. Arch Gen Psychiatry 53:323331

Abelson JL, Liberzon I (1999): Dose response of adrenocorticotropin and cortisol to the CCK-B agonist pentagastrin. Neuropsychopharmacology 21:485-494

Abelson JL, Nesse RM (1994): Pentagastrin infusions in patients with panic disorder. I. Symptoms and cardiovascular responses. Biol Psychiatry 36:73-83

Abelson JL, Nesse RM, Vinik AI (1994): Pentagastrin infusions in patients with panic disorder. II. Neuroendocrinology. Biol Psychiatry 36:84-96

Abelson JL, Weg JG, Nesse RM, Curtis GC (1996): Neuroendocrine responses to laboratory panic: Cognitive intervention in the doxapram model. Psychoneuroendocrinology 21:375-390

Aguilera G (1994): Regulation of pituitary ACTH secretion during chronic stress. Frontiers Neuroendocrinol 15:321-350 
Altemus M, Pigott T, Kalogeras KT, Demitrack M, Dubbert B, Murphy DL, Gold PW (1992): Abnormalities in the regulation of vasopressin and corticotropin releasing factor secretion in obsessive-compulsive disorder. Arch Gen Psychiatry 49:9-20

Beinfeld MC (1983): Cholecystokinin in the central nervous system: A minireview. Neuropeptides 3: 411-427

Bichet D, Kortas C, Mettauer B, Manzini C, Marc-Aurèle J, Rouleau JL, Schrier RW (1986): Modulation of plasma and platelet vasopressin by cardiac function in patients with heart failure. Kidney Int 29:1188-1196

Biró E, Sarnyai Z, Penke B, Szabó G, Telegdy G (1993): Role of endogenous corticotropin-releasing factor in mediation of neuroendocrine and behavioral responses to cholecystokinin octapeptide sulfate ester in rats. Neuroendocrinology 57:340-345

Bondy CA, Jensen RT, Brady LS, Gainer H (1989): Cholecytokinin evokes secretion of oxytocin and vasopressin from the rat neural lobe independent of external calcium. Proc Natl Acad Sci U S A 86:5198-5201

Born J, Ditschuneit I, Schreiber M, Dodt C, Fehm H (1995): Effects of age and gender on pituitary-adrenocortical responsiveness in humans. Eur J Endocrinol 132:705711

Bradwejn J, Koszycki D (1994): The cholecystokinin hypothesis of anxiety and panic disorder. Ann N Y Acad Sci 713:273-282

Bradwejn J, Koszycki D, du Tertre AC, van Megan H, den Boer J, Westenberg H, Annable L (1994): The panicogenic effects of cholecystokinin-tetrapeptide are antagonized by L-365,260, a central cholecystokinin receptor antagonist, in patients with panic disorder. Arch Gen Psychiatry 51:486-493

Bradwejn J, Koszycki D, Shriqui C (1991): Enhanced sensitivity to cholecystokinin tetrapeptide in panic disorder. Arch Gen Psychiatry 48:603-610

Calogero AE, Nicolosi AM, Moncada ML, Coniglione F, Vicari E, Polosa P, D'Agata R (1993): Effects of cholecystokinin octapeptide on the hypothalamic-pituitaryadrenal axis function and on vasopressin, prolactin, and growth hormone release in humans. Neuroendocrinology 58:71-76

Chen DY, Deutsch JA, Gonzalez MF, Gu Y (1993): The induction and suppression of c-fos expression in the rat brain by cholecystokinin and its antagonist L364,718. Neurosci Lett 149:91-94

Davis M (1998): Are different parts of the extended amygdala involved in fear versus anxiety? Biol Psychiatry 44:1239-1247

de Montigny C (1989): Cholecystokinin tetrapeptide induces panic-like attacks in healthy volunteers. Arch Gen Psychiatry 46:511-517

de Wied D, Diamant M, Fodor M (1993): Central nervous system effects of the neurohypophyseal hormones and related peptides. Frontiers Neuroendocrinol 14:251-302

DeBold CR, Sheldon WR, DeCherney GS, Jackson RV, Alexander AN, Vale W, Rivier J, Orth DN (1984): Arginine vasopressin potentiates adrenocorticotropin release induced by ovine corticotropin-releasing factor. J Clin Invest 73:533-538

DeCherney GS, DeBold CR, Jackson RV, Sheldon WR, Island
DP, Orth DN (1985): Diurnal variation in the response of plasma adrenocorticoptropin and cortisol to intravenous ovine corticotropin-releasing hormone. J Clin Endocrinol Metab 61:273-279

Degli Uberti EC, Trasforini G, Margutti AR, Rotola CA, Pansini R (1983): Effect of pentagastrin on adrenocorticotropin hormone and thyroid-stimulating hormone release in normal subjects. Horm Res 17:74-77

Dillon DJ, Gorman JM, Liebowitz MR, Fyer AJ, Klein DF (1987): Measurement of lactate-induced panic and anxiety. Psychiatry Res 20:97-105

Dinan TG, Lavelle E, Scott LV, Newell-Price J, Medbak S, Grossman AB (1999): Desmopressin normalizes the blunted adrenocorticotropin response to corticotropinreleasing hormone in melancholic depression: Evidence of enhanced vasopressinergic responsivity. J Clin Endocrinol Metab 84:2238-2240

Ehrenreich H, Stender N, Gefeller O, tom Dieck K, Schilling L, Kaw W (1996): A novelty-related sustained elevation of vasopressin plasma levels in young men is not associated with an enhanced response of adrenocorticotropic hormone $(\mathrm{ACTH})$ to human corticotropin releasing factor (hCRF). Res Exp Med 195:291-299

Geracioti TD, Ekhator NN, Nicholson WE, Arndt S, Loosen PT, Orth DN (1999): Intra- and inter-individual correlations between cholecystokinin and corticotropin-releasing hormone concentrations in human cerebrospinal fluid. Depress Anxiety 10:77-80

Harro J, Vasar E, Bradwejn J (1993): CCK in animal and human research on anxiety. Trends Pharmacol Sci 14:244-249

Hensen J, Hader O, Bahr V, Oelkers W (1988): Effects of incremental infusions of arginine vasopressin on adrenocorticotropin and cortisol secretion in man. J Clin Endocrinol Metab 66:668-671

Hermus ARMM, Pieters GFFM, Smals AGH, Benraad TJ, Kloppenborg PWC (1984): Plasma adrenocorticotropin, cortisol, and aldosterone responses to corticotropinreleasing factor: Modulatory effects of basal cortisol levels. J Clin Endocrinol Metab 58:187-191

Hinks GL, Poat JA, Hughes J (1995): Changes in hypothalamic cholecystokinin ${ }_{\mathrm{A}}$ and cholecystokinin ${ }_{\mathrm{B}}$ receptor subtypes and associated neuropeptide expression in response to salt-stress in the rat and mouse. Neuroscience 68:765-781

Holsboer F, Barden N (1996): Antidepressants and hypothalamic-pituitary-adrenocortical regulation. Endocrinol Rev 17:187-205

Insel TR, O'Brien DJ, Leckman JF (1999): Oxytocin, vasopressin, and autism: Is there a connection? Biol Psychiatry 45:145-157

Kamilaris TC, Johnson EO, Calogero AE, Kalogeras KT, Bernardini R, Chrousos GP, Gold PW (1992): Cholecystokinin-octapeptide stimulates hypothalamic-pituitaryadrenal function in rats: Role of corticotropin-releasing hormone. Endocrinology 130:1764-1774

Kellner M, Herzog L, Holsboer F, Wiedemann K (1995): Circadian changes in the sensitivity of the corticotropinreleasing hormone-stimulated HPA system after arginine vasopressin and atrial natriuretic hormone in human male controls. Psychoneuroendocrinology 20:515-524 
Kiss JZ, Willians TH, Palkovits M (1984): Distribution and projections of cholecystokinin immunoreactive neurons in the hypothalamic paraventricular nucleus of the rat. J Comp Neurol 227:173-181

Larsson LI, Rehfeld JF (1981): Pituitary gastrins occur in corticotrophs and melanotrophs. Science 213:768-770

Le Mellédo JM, Bradwejn J, Koszycki D, Bellavance F, Bichet DG (in press): The effects of CCK-4 on vasopressin and oxytocin in healthy women and in women suffering from premenstrual dysphoric disorder. Peptides (in press)

Le Mellédo JM, Bradwejn J, Koszycki D, Boulanger JP, Cadieux A, Bellavance G, Bichet DG (1997): The role of the B-adrenergic system in behavioral and neuroendocrine response to CCK-4. NCDEU Annual Meeting, May 9, 1997, Ft. Lauderdale, Florida.

LeDoux J (1998): Fear and the brain: Where have we been, and where are we going? Biol Psychiatry 44:1229-1238

Liebsch G, Wotjak CT, Landgraf R, Engelmann M (1996): Septal vasopressin modulates anxiety-related behaviour in rats. Neurosci Lett 217:101-104

Lindefors N, Lindén A, Brené S, Sedvall G, Persson H (1993): CCK peptides and mRNA in the human brain. Prog Neurobiol 40:671-690

Linkowski P, Medlewicz J, Leclercq R, Brasseur M, Hubain P, Golstein J, Copinschi G, Van Cauter E (1985): The 24hour profile of adrenocorticotropin and cortisol in major depressive illness. J Clin Endocrinol Metab 61:429-438

Mannuzza S, Fyer AJ, Endicott J, Klein DF (1985): Family Informant Schedule and Criteria. New York, NY, New York State Psychiatric Institute

Matsumura M, Yamanoi A, Yamamoto S, Saito S (1983): In vivo and in vitro effects of cholecystokinin octapeptide on the release of $\beta$-endorphin-like-immunoreactivity. Neuroendocrinology 36:443-448

Mezey E, Reisine TD, Skirboll L, Beinfeld M, Kiss JZ (1986): Role of cholecystokinin in corticotropin release: Coexistence with vasopressin and corticotropin-releasing factor in cells of the rat hypothalamic paraventricular nucleus. Proc Natl Acad Sci U S A 83:3510-3512

Miaskiewicz SL, Stricker EM, Verbalis JG (1989): Neurohypophyseal secretion in response to cholecystokinin but not meal-induced gastric distention in humans. J Clin Endocrinol Metab 68:837-843

Millington WR, Mueller GP, Lavigne GJ (1992): Cholecystokinin type $A$ and type $B$ receptor antagonists produce opposing effects on cholecystokinin-stimulated $\beta$-endorphin secretion from the rat pituitary. J Pharmacol Exp Ther 261:454-461

Morawska-Barszczewska J, Guzek JW, Kaczorowska-Skora J (1996): Cholecystokinin octapeptide and the daily rhythm of vasopressin and oxytocin release. Exp Clin Endocrinol Diabetes 104:164-171

Purba JS, Hoogendijk WJG, Hofman MA, Swaab DF (1996): Increased number of vasopressin- and oxytocinexpressing neurons in the paraventricular nucleus of the hypothalamus in depression. Arch Gen Psychiatry 53:137-143

Rehfeld JF (1978): Localization of gastrins to neuro- and adenohypophysis. Nature (London) 271:771-773

Rehfeld JF, Larsson LI (1981): Pituitary gastrins: Different processing in corticotrophs and melanotrophs. J Biol Chem 256:10426-10429

Rehfeld JF, Lindholm J, Andersen BN, Bardram L, Cantor P, Fenger M, Lüdecke DK (1987): Pituitary tumors containing cholecystokinin. N Eng J Med 316:1244-1247

Reisine T, Jensen R (1986): Cholecystokinin-8 stimulates adrenocorticotropin release from anterior pituitary cells. J Pharmacol Exp Ther 236:621-626

Saito A, Sankaran H, Goldfine ID, Williams JA (1980): Cholecystokinin receptors in brain: Characterization and distribution. Science 208:1155-1156

Schürmeyer TH, Avgerinos PC, Gold PW, Gallucci WT, Tomai TP, Cutler GB, Loriaux DL, Chrousos GP (1984): Human corticotropin-releasing factor in man: Pharmacokinetic properties and dose-response of plasma adrenocorticotropin and cortisol secretion. J Clin Endocrinol Metab 59:1103-1108

Siegel RA, Düker EM, Pahnke U, Wuttke W (1987): Stressinduced changes in cholecystokinin and substance $\mathrm{P}$ concentrations in discrete regions of the rat hypothalamus. Neuroendocrinology 46:75-81

Späth-Schwalbe E, Piroth L, Pietrowsky R, Born J, Lorenz Fehm H (1988): Stimulation of the pituitary adrenocortical system in man by cerulein, a cholecystokinin-8-like peptide. Clin Physiol Biochem 6:316-320

Stoehr JD, Cheng SWT, North WG (1993): Homozygous Brattleboro rats display attenuated conditioned freezing responses. Neurosci Lett 153:103-106

van Londen L, Goekoop JG, van Kempen GMJ, Frankhuijzen-Sierevogel AC, Wiegant VM, van der Velde EA, De Wied D (1997): Plasma levels of arginine vasopressin elevated in patients with major depression. Neuropsychopharmacology 17:284-292

Vanderhaeghen JJ, Goldman S, Lotstra F, Van Reeth O, Deschepper C, Rossier J, Schiffmann S (1985): Co-existence of cholecystokinin- or gastrin-like peptides with other peptides in the hypophysis and hypothalamus. Ann N Y Acad Sci 448:334-344

Verbalis JG, Richardson DW, Stricker EM (1987): Vasopressin release in response to nausea-producing agents and cholecystokinin in monkeys. Am J Physiol 252:R749-R753

Woodruff GN, Hill DR, Boden P, Pinnock R, Singh L, Hughes J (1991): Functional role of brain CCK receptors. Neuropeptides 19(suppl):45-56

Wotjak CT, Kubota M, Liebsch G, Montkowski A, Holsboer F, Neumann I, Landgraf R (1996): Release of vasopressin within the rat paraventricular nucleus in response to emotional stress: A novel mechanism of regulating adrenocorticotropic hormone secretion? J Neurosci 16:7725-7732 